\title{
Experimental and Numerical investigation of Heat transfer enhancement using Al2O3- Ethylene Glycol/Water nanofluids in straight channel
}

\author{
Mohammed K. Mohammed ${ }^{1, ~}$, Abdolbaqi M. $\mathrm{Kh}^{2}$, Thamir K. Ibrahim², Rizalman Bin \\ Mamat $^{2}$ and Omar I. Awad ${ }^{2}$ \\ ${ }^{1}$ Mechanical Engineering Department, University of Sharjah, UAE \\ ${ }^{2}$ Faculty of Mechanical Engineering, University Malaysia Pahang, 26600 Pekan, Pahang, Malaysia
}

\begin{abstract}
A study of computational fluid dynamics has been conducted to study the characteristics of the heat transfer and friction factor of A12O3/Ethylene glycol-water nanofluid flowing in straight channel. The three dimensional realizable $\mathrm{k}-\square$ turbulent model with enhanced wall treatment was utilized. As well as were used Temperature dependent thermophysical properties of nanofluid and water. The evaluation of the overall performance of the tested channel was predicated on the thermohydrodynamic performance index. The obtained results showed that the difference in behaviour depending on the parameter that has been selected to compare the nanofluid with the base fluid. In addition, the friction factor and the heat transfer coefficient increases with an increase of the nanoparticles volume concentration at the same Reynolds number. The penalty of pressure drop is negligible with an increase of the volume concentration of nanoparticles. Conventional correlations that have been used in turbulent flow regime to predict average heat transfer and friction factor are Dittus-Boelter and Blasius correlations, for channel are also valid for the tested nanofluids which consider that the nanofluids have a homogeneous fluid behave.
\end{abstract}

\section{Introduction}

Using heat transfer enhancement techniques, can improve thermal performance of a tubes [13]. The heat transfer techniques can be classified in to three broad techniques: Passive techniques that do not need external power such as rough surfaces, swirl flow devices, treated surfaces, extended surfaces, displaced enhancement devices, surface tension device, coiled tube and additives such as nanoparticles: Active technique that need external power to enable the wanted flow modification for increasing heat transfer such as electrostatic fields, mechanical aids, jet impingement, suction, injection, surface vibration, and fluid vibration: Compound technique is the mix of two or more of the techniques that mentioned above at one time. There are many applications of heat transfer augmentation by using nanofluids to

*Corresponding author: thamir@ump.edu.my 
get the cooling challenge necessary such as the photonics, transportation, electronics, and energy supply industries [4-10].A double tube coaxial heat exchanger heated by solar energy using Aluminium oxide nanofluid presented experimentally and numerically by [11]. Forced convection turbulent flow of nanofluid $\left(\mathrm{Al}_{2} \mathrm{O}_{3}\right.$ / water) with variable wall temperature inside an annular tube has been experimentally investigated by [12]. The results shown due to the nanoparticle presence in the fluid the heat transfer has been enhanced. Horizontal doubletube heat exchanger counter turbulent flow studied numerically by $[13,14]$. The study has been included both experimental and simulation by FLUENT software. The results showed that significant of the nanofluid in heat transfer enhancement and also, good agreement with other experimental data. The turbulent flow of nanofluids $\left(\mathrm{TiO}_{2}, \mathrm{Al}_{2} \mathrm{O}_{3}\right.$ and $\left.\mathrm{CuO}\right)$ with different volume concentrations flowing through a duct under constant heat flux condition with two-dimensional model has been analysed numerically [15]. The effects of nanoparticle volume concentration (1-10\% Al2O3) in base fluid of ethylene glycol-water mixture was studied in both numerically and experimentally, where the results showed that with an increase of particle concentration at constant Reynolds number the enhance of heat transfer rate increased considerably [16].

In the current study, the enhancement of heat transfer in the straight square channel is carried out. The CFD analysis by ANSYS FLUENT15 software using the finite volume method is adopted. The heat flux, Reynolds numbers and the $\mathrm{Al}_{2} \mathrm{O}_{3}$ volume concentration are $\left(5000 \mathrm{~W} / \mathrm{m}^{2}\right),\left(10^{4}-10^{5}\right)$ and $(2,3$ and $4 \%)$ respectively. The nanofluids of $\mathrm{Al}_{2} \mathrm{O}_{3}$ dispersed to (60:40\%) Ethylene Glycol water is utilized. Results were validated by comparison with experimental data in the literatures.I

\section{Experimental Procedure}

\subsection{Nanofluid preparation}

The nanofluids preparation can be classified into two different methods. The first technique is one step process. Where the nanoparticles are synthesized and immediately dispersed in a base fluid. The second technique is two-step process. Firstly the metal particles are produced in form of nano-powder, and then the nano particles dispersed in the base fluid. The difficulties of this method are overcoming the sedimentation and stability of prepared nanofluids. $\mathrm{Al}_{2} \mathrm{O}_{3}$ nanoparticle of $13 \mathrm{~nm}$ size procured from Sigma-Aldrich is used in the present study by following the preparation steps which explained by [17]. Alumina $\left(\mathrm{Al}_{2} \mathrm{O}_{3}\right)$ dispersed in (60:40\%) ethelyene glycol/distilled water nanofluid is prepared using two-step method.

\subsection{Thermal properties measurement}

The nanofluid thermal properties are measured experimentally in the nano-laboratory of university Malaysia Pahang. The thermal conductivity of nanofluid is measured with KD2 Pro thermal property analyzer of Decagon Devices, Inc., USA. The investigators who were used KD2 pro in their measurement of thermal conductivity KD2 Pro transient hotwire thermal conductivity meter [18-20] and other researchers. The KD2 Pro transient hotwire thermal conductivity meter is used to determine the thermal conductivity of the present sample. The sensor is calibrated by determining the thermal conductivity of distilled water and glycerin. The measured values at room temperature are 0.610 and $0.280 \mathrm{~W} / \mathrm{mK}$, respectively for distilled water and glycerin, which are in agreement with values in literature of 0.613 and $0.285 \mathrm{~W} / \mathrm{mK}$, respectively, within $\pm 5 \%$ accuracy. Furthermore a water bath is used to maintain a constant temperature within $0.1{ }^{\circ} \mathrm{C}$. In order to ensure the measurement 
within $5 \%$, at least five measurements were taken for each concentration at a specific temperature as explained by [21] and [22]. Furthermore, a commercial Brookfield DV-I prime viscometer has been used for the nanofluid viscosity measurement at temperature of $25^{\circ} \mathrm{C}$. Firstly, distilled water has been utilized to calibrate the viscosity measurement. Then the viscosity of nanofluids were measured. Simplicity, the hot wire method was used for thermal conductivity measurement and viscometer utilized for viscosity measurement.

\subsection{Thermal properties measurement}

The density $\left(\rho_{n f}\right)$, specific heat capacity $\left(C_{n f}\right)$, thermal conductivity $\left(k_{n f}\right)$ and viscosity $\left(\mu_{n f}\right)$ of nanofluid is obtained by the relation [23].

$$
\begin{aligned}
& \rho_{n f}=\left(\frac{\phi}{100}\right) \rho_{p}+\left(1-\frac{\phi}{100}\right) \rho_{f} \\
& C_{n f}=\frac{\frac{\phi}{100}(\rho C)_{p}+\left(1-\frac{\phi}{100}\right)(\rho C)_{f}}{\rho_{n f}} \\
& k_{r}=\frac{k_{n f}}{k_{f}}=0.8938\left(1+\frac{\phi}{100}\right)^{1.37}\left(1+\frac{T_{n f}}{70}\right)^{0.2777}\left(1+\frac{d_{p}}{150}\right)^{-0.0336}\left(\frac{\alpha_{p}}{\alpha_{f}}\right)^{0.01737} \\
& \mu_{r}=\frac{\mu_{n f}}{\mu_{f}}=\left(1+\frac{\phi}{100}\right)^{11.3}\left(1+\frac{T_{n f}}{70}\right)^{-0.038}\left(1+\frac{d_{p}}{170}\right)^{-0.061}
\end{aligned}
$$

The assumption of a problem undertaken is that the nanofluid behaves as a Newtonian fluid for concentration less than $4.0 \%$. The properties of the solid particles are taken to be steady in the present operating temperature of $293 \mathrm{~K}$.

Overall Efficiency is the ratio between the net energy produced in the electric generator and thermal energy entering the generating unit as a result of fuel combustion, and can be calculated from the following equation [24].

$$
\eta_{o}=\frac{3600 * p}{\dot{m} * L H V_{f}+\sum \text { HeatCredits }}
$$

\section{Numerical Model}

The numerical calculation has been carried out using CFD code (ANSYS FLUENT 15) for the studied geometries. The governing equations have been solved at every cell for all values of flow, pressure and temperature. Where the first step involving to creation of the three dimensional geometric models of the undertaken problem using design modeller followed by the second step which is model mesh generation in ANSYS software. The straight channel geometry considered is illustrated in Fig. 1. In the current study, to represent flow in the numerical simulation was used the Cartesian coordinate system $(\mathrm{x}, \mathrm{y}, \mathrm{z})$. The heat transfer and turbulent flow were established simultaneously downstream in the tubes. Additionally, the inlet boundary conditions of the water or nanofluid were set as velocity inlets likewise the pressure outlets were selected for the outlet boundary conditions. Moreover, constant heat 
flux of $5000 \mathrm{w} / \mathrm{m}^{2}$ has been applied to the exterior wall. The channel material is copper, where the physical properties of copper are taken as constant density $q=8978 \mathrm{~kg} / \mathrm{m} 3$, specific heat $\mathrm{Cp}=381 \mathrm{~J} /(\mathrm{kg} \mathrm{K})$, and thermal conductivity $\mathrm{K}=387.6 \mathrm{~W} /(\mathrm{m} \mathrm{K})$.

\subsection{Physical model}

The assumption of this study limited to be steady state, incompressible and Newtonian turbulent fluid flow, constant thermophysical properties of nanofluid, no effect of gravity and heat conduction in the axial direction. High Reynolds number as input parameter estimated; pressure treatment adopted with $3 \mathrm{D}$ realizable $\mathrm{k}-\varepsilon$ turbulent model with enhanced wall treatment employed, converged solutions considered for residuals lower than 25000 for all the governing equations. The results of simulation for channel with nanofluids compared with the equations of Blasius Eq. 5. for friction factor and Dittus-Boelter Eq.7 for Nusselt number.

The assumption of a problem undertaken is that the nanofluid comports as a Newtonian fluid for concentration less than $4.0 \%$. For conditions of dynamic similarity for flow of the two media, nanoparticles and base fluid in tube, the friction coefficients can be written as follows [25].

$$
f_{f}=\frac{0.316}{\operatorname{Re}^{0.25}}
$$

The system of governing criteria can be written as:

Numbers of investigators derive the empirical correlation from experimental data. [2628]

$$
f_{r}=\frac{f_{n f}}{f_{f}}=1.078\left[\left(\frac{\rho_{n f}}{\rho_{f}}\right)^{-0.514}\left(\frac{\mu_{n f}}{\mu_{f}}\right)^{-0.1248}\right]
$$

Forced convection heat transfer coefficient under turbulent flow may be estimated by Dittus-Boelter Eq. 7. for base fluid in the range of Reynolds number $10^{4}<\operatorname{Re}<10^{5}$.

$$
N u=\frac{h_{f}}{k_{f}} D=0.023 \operatorname{Re}^{0.8} \operatorname{Pr}^{0.4}
$$

The modified Dittus-Boelter Eq. 7 is applicable for both base fluid and nanofluids with spherical shaped nanoparticles dispersed in water as [14].

$$
N u_{n f}=\frac{h_{n f}}{k_{n f}} D=0.023 \operatorname{Re}^{0.8} \operatorname{Pr}_{f}^{0.4}\left(1+\operatorname{Pr}_{n f}\right)^{-0.012}(1+\phi)^{0.23}
$$

Reynolds number depending on the diameter of the tube can be defined as:

$$
\operatorname{Re}=\frac{\rho_{n f} \times D \times u}{\mu_{n f}}
$$




\subsection{Governing equations}

The realizable k- $\varepsilon$ turbulence model with wall heat treatment is used for turbulent flow simulation. The Realizable turbulence model by Shih et al.[29] is the most sophisticated model newly of the three k- $\varepsilon$ differences and characteristics two main variations from the standard $k-\varepsilon$ model. It utilizes a new equation for the turbulent viscosity equation and derived the dissipation rate transport equation from the mean-square vorticity fluctuation equation. Turbulent kinetic energy, $\mathrm{k}$, and turbulent dissipation rate, $\varepsilon$, are combined to the governing equations using the relation of the turbulent viscosity $\mu_{t}=\rho C_{\mu} K^{2} / \varepsilon$, where $C \mu=0.09$ and the following values have been assigned as an empirical constant:

$\mathrm{C}_{2}=1.9, \sigma_{\tau}=0.85, \sigma_{\kappa}=1.0$ and,$\sigma_{\varepsilon}=1.2$.

$$
k=\frac{3}{2}(u . I)^{2}, \varepsilon=C_{\mu}^{3 / 4} \frac{k^{3 / 2}}{L}
$$

Furthermore, the character L. in Eq. 10 refer to the turbulent characteristic length scale, which is set to be $0.07(\mathrm{~d} / 2)$ in the current study. As well as the factor of 0.07 been adopted based on the maximum value of the mixing length in fully developed turbulent pipe flow. For an initial guess of turbulent quantities $(k$ and $\varepsilon)$, the turbulent intensity $(I)$ was specified. Where the turbulent intensity for each case can be calculated based on the Eq. 11 . [30].

$$
I=0.16 \times \mathrm{Re}^{-1 / 8}
$$

With regards to the nanofluid, infinitesimal (less than $100 \mathrm{~nm}$ ) solid particles assumed to be able using single phase approach, so single phase approach adopted for nanofluid modelling. For all these assumptions, the dimensional conservation equations for steady state mean conditions are as follows: continuity, momentum and energy equations.[31].

$$
\begin{aligned}
& \frac{\partial u}{\partial x}+\frac{1}{r} \frac{\partial}{\partial r}\left(r \rho_{n f} u\right)=0 \\
& u \frac{\partial u}{\partial x}+v \frac{\partial}{\partial r}\left(\rho_{n f} u\right)=-\frac{\partial p}{\partial x}+\frac{1}{r} \frac{\partial}{\partial r}\left[r\left(v+\varepsilon_{H}\right) \frac{\partial u}{\partial r}\right] \\
& \frac{1}{r} \frac{\partial}{\partial r}(\rho u T)=\frac{1}{r} \frac{\partial}{\partial r}\left[r\left(\alpha+\varepsilon_{H}\right) \frac{\partial T}{\partial r}\right]+\frac{1}{r^{2}} \frac{\partial}{\partial x}\left\{\left\{\frac{k_{n f}}{C_{p}} \frac{\partial T}{\partial x}\right\}\right.
\end{aligned}
$$

\subsection{Grid independent test}

A careful checking for the grid independent was conducted among three systems to ensure the validity and exactness of the numerical results. Fig. 1 shows the flat grid topology utilized for the $3 \mathrm{D}$ grid system. The mesh generated for four sets with various grid densities from $4.26 \times 10^{8}$ cells $/ \mathrm{m}^{3}$ to $8.81 \times 10^{8}$ cells $/ \mathrm{m}^{3}$, where the grid density is the number of grids (cells) per unit volume of modeled tube. Fig. 2 illustrate the friction factor and Nusselt number versus grid density for the circular tube at Re of 10000 and mixture of ethylene glycol-water with $20^{\circ} \mathrm{C}$ inlet temperature. It is clarified that the refinement after a mesh density of $5.88 \times 108$ cells $/ \mathrm{m} 3$ does not effect on the values of the Nusselt number or friction factor in any form and based on this density a mesh is chosen for analysis. 


\section{Results and discussion}

\subsection{Code validation}

The verification process is very important to check the results. It can be perceived in Fig. 3 . with an increase of Reynolds number, the friction factor decreases under turbulent flow condition. The Blasius Eq. 5 results indicated as a solid black line. It appears that good agreement among the CFD results and the equations. Fig. 4. shows comparison among the equation that provided by Dittus-Boelter Eq. 7 and the collected data of [12] with the calculated values of the Nusselt numbers for $\mathrm{Al}_{2} \mathrm{O}_{3}$ nanofluid Ethylin glycol- water mixture. As observed, an excellent agreement has been obtained with calculated values from theoretical equation within a wide range of Reynolds numbers. It can be seen the DittusBoelter correlation and the collected data indicated as a dashed and solid black lines respectively.

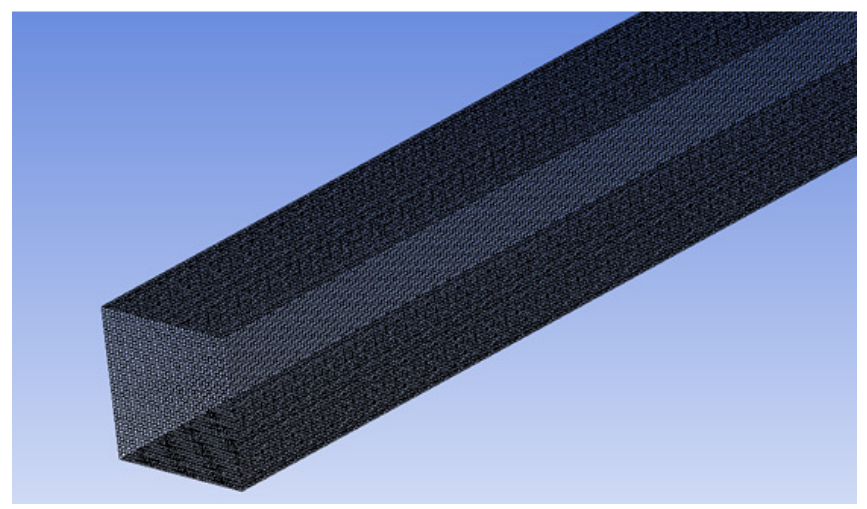

Fig. 1. Square channel mesh.

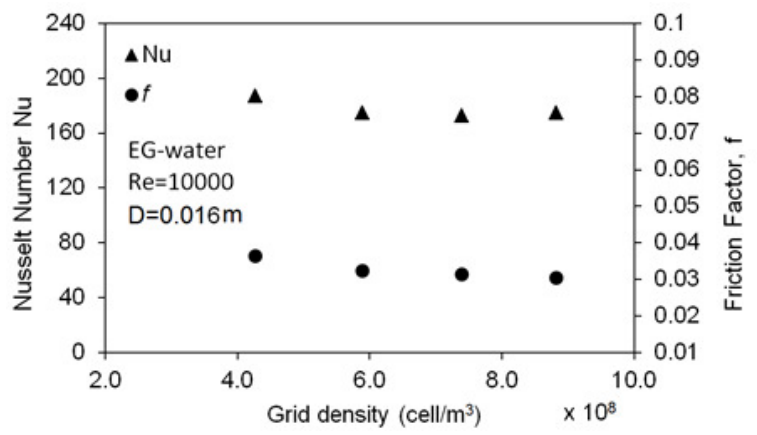

Fig. 2. The friction factor and Nusselt number versus grid density for the circular tube. 


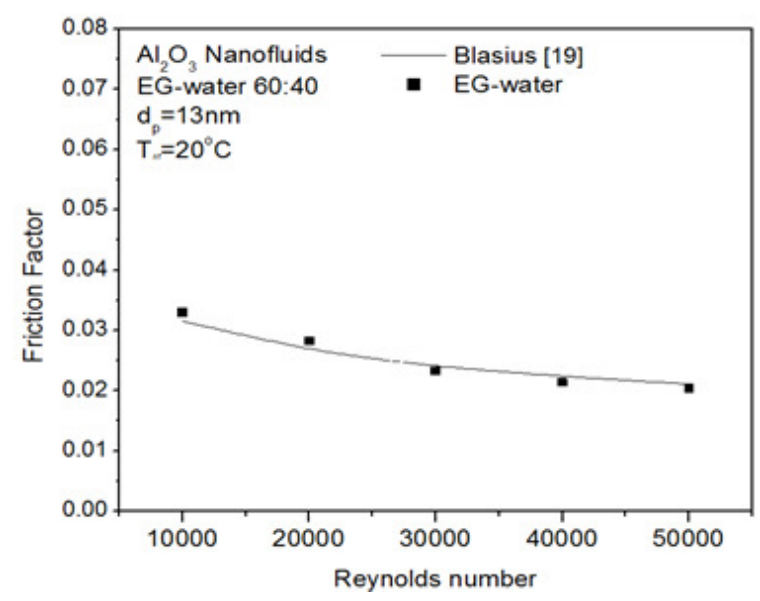

Fig. 3. Validation of Friction factor in present numerical simulation.

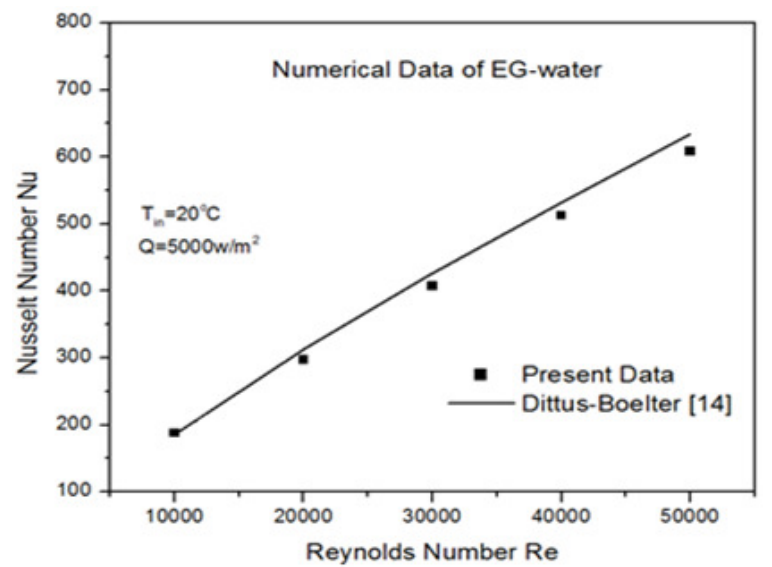

Fig. 4. Validation of Nusselt number in present numerical simulation.

\subsection{The effect of nanofluid volume fraction}

Heat transfer coefficient for $\mathrm{Al}_{2} \mathrm{O}_{3}$ nanofluid and $2 \%$ to $4 \%$ volume fraction with Reynolds number demonstrates in Fig. 5. It seems that the nanofluid volume concentration effect is significant. Where the increase in volume fraction enhance the heat transfer rate. Since the increase in the volume concentration gainful but that increase must take into account the pumping power. As well as the heat transfer coefficient for ethylene glycol-water mixture 60:40 indicated also in Fig. 5, in addition the percentage of mixing the base fluid play an important role to enhance the heat transfer rate through changing base fluid thermophysical properties such as viscosity, density, specific heat capacity and thermal conductivity. While Fig. 6. illustrated the Nusselt number enhancement ratio versus Reynolds number at different nanoparticles of $\mathrm{Al}_{2} \mathrm{O}_{3}$ with volume fraction of ( 2,3 and 4) \% in circular tube. The enhancement in Nusselt number clearly can be seen, where the volume concentration of $4 \%$ has the highest enhance followed by 3 and $2 \%$. 


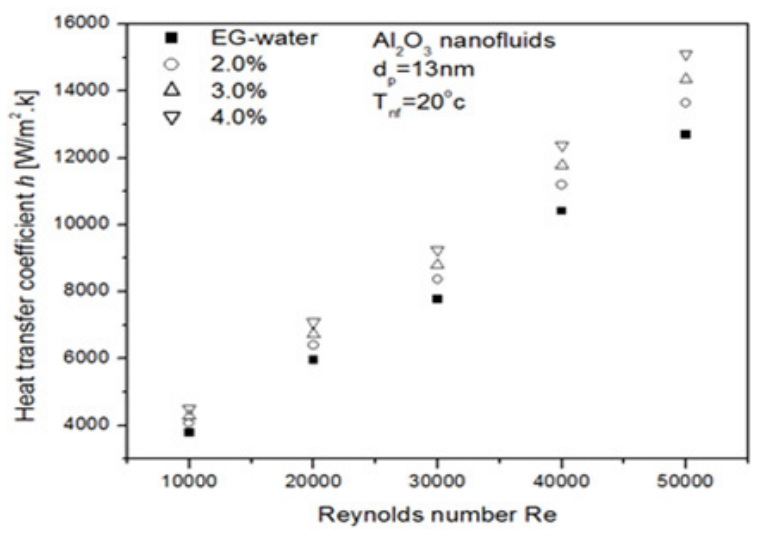

Fig. 5. Heat transfer coefficient ratio versus Reynolds number for circular tube

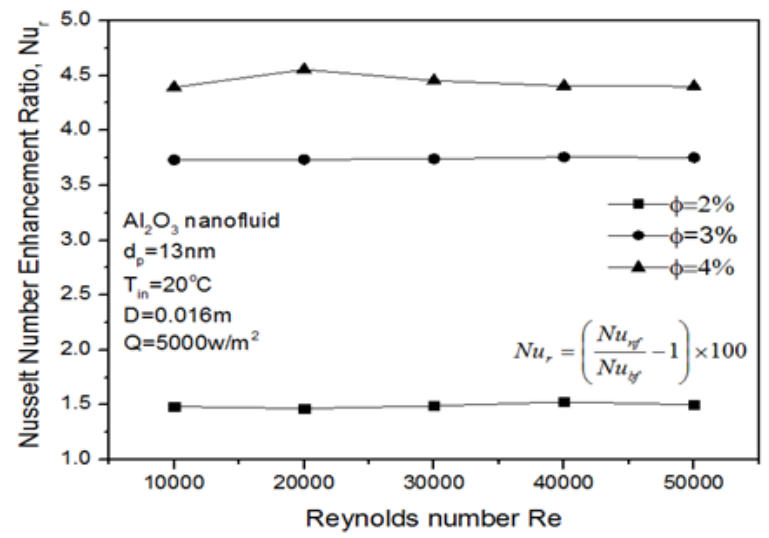

Fig. 6. Nusselt number enhancement ratio versus Reynolds number

\subsection{Effect of nanoparticles type and concentration on wall shear stress}

The variation of the wall shear stress for $\left(\mathrm{CuOandTiO}_{2}\right)$ nanofluids with respect to the distance from the inlet section of the channel at Reynolds number $10^{6}$ and $\phi=2$ and $4 \%$ are plotted in Fig. 7. It can be observed that the wall shear stress varies depending on the type of nanoparticles. This condition is due to the variation in effective dynamic viscosity for different types of nanofluid [32]. 


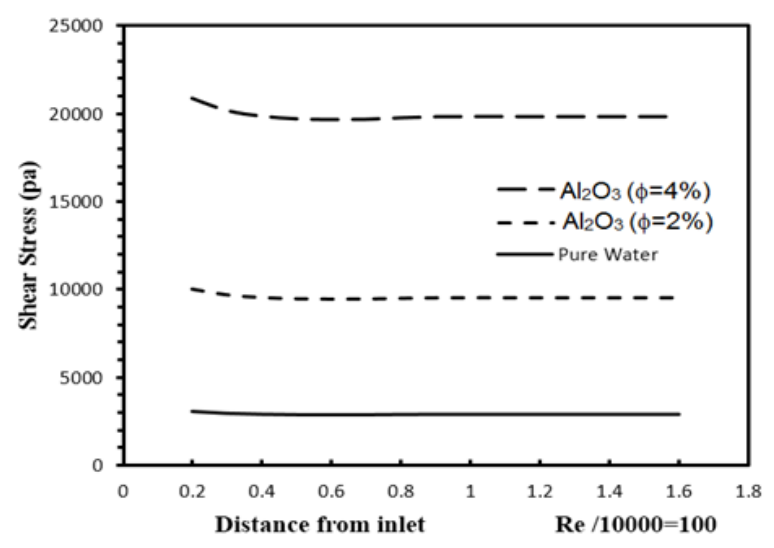

Fig. 7. Shear stress for $\left(\mathrm{CuOandTiO}_{2}\right)$ nanofluids $\left(\mathrm{CuOandTiO}_{2}\right)$ with respect to inlet distance.

Fig. 8 shows the relationship between the Reynolds number and the shear stress for different volume concentrations, $\phi=2,3$ and $4 \%$. The shear stress increases with Reynolds number. Further, it will increase the secondary flow, decrease the thermal boundary layer and subsequently increase the Nusselt number $[33,34]$. The reduction in velocities leads to increase in wall shear resistance and subsequently provides more heat dissipation with the nanofluids $[35,36]$.

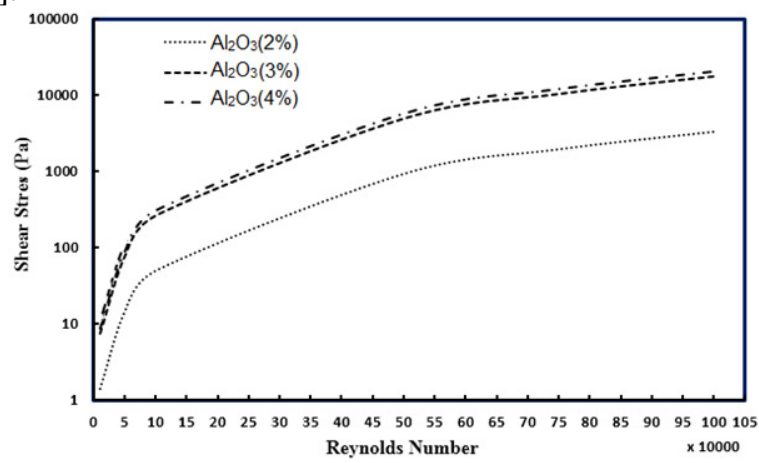

Fig. 8. Reynolds number and shear stress for different volume fractions.

\section{Conclusion}

In the present study, Thermal properties of $\mathrm{Al}_{2} \mathrm{O}_{3}$ nanoparticles suspended in ethylene glycolwater calculated depending on the experimental data of [12]. Forced convection heat transfer under turbulent flow by numerical simulation with uniform heat flux boundary condition of straight tube studied. The heat transfer enhancement due to various parameters such as Reynolds number and nanoparticle volume concentration reported. The governing equations has been solved using finite volume method with specific presumptions and proper boundary conditions. The Nusselt number and friction factor obtained through the numerical simulation. The $4 \%$ volume concentration of nanofluid has the highest values of Nusselt number, followed by $(3,2$, and $0 \%)$. There is a good agreement among the CFD analysis of Nusselt number and friction factor of nanofluid with experimental data of [12]. With deviation not more than $10 \%$. 
The authors would like to thank Universiti Malaysia Pahang for provides laboratory facilities and financial support under research grant (RDU 150334).

\section{References}

1. A.M. Mhamuad, T.K. Ibrahim, R.R. Jasim, Tikrit J. Eng.Sci. (TJES), 15: 63-78 (2008).

2. T.K. Ibrahim, F. Basrawi, M.N. Mohammed, H. Ibrahim, J. Eng. Appl. Sci., 11: 5 (2016).

3. T.K. Ibrahim, Investigating the Matrix Geometry Shape Effects on the performance of the Rotary Heat Exchanger in the Dorah Power Plant, Tikrit J. Eng.Sci. (TJES), 16 (2009) 51-65.

4. M.K. Abdolbaqi, C. Azwadi, R. Mamat, Heat transfer augmentation in the straight channel by using nanofluids, Case Studies in Therm. Eng., 3: 59-67 (2014).

5. M.K. Abdolbaqi, N.A.C. Sidik, R. Mamat, W.H. Azmi, Int. Commun. Heat. Mass., 69: 34-40 (2015).

6. M.K. Abdolbaqi, W. Azmi, R. Mamat, N. Mohamed, G. Najafi, Int. Commun. Heat. Mass., 75: 295-302 (2016).

7. M.K. Abdolbaqi, W. Azmi, R. Mamat, K. Sharma, G. Najafi, Appl. Therm. Eng., 102: 932-941 (2016).

8. M.K. Abdolbaqi, C. Azwadi, R. Mamat, W. Azmi, G. Najafi, Int. J. Automot. Mech. Eng., 11 (2015).

9. M.K. Abdolbaqi, R. Mamat, N.A.C. Sidik, The Effects of Turbulent Nanofluids and Secondary Flow on the Heat Transfer through a Straight Channel (2015)

10. M.K. Abdolbaqi, N.A.C. Sidik, W.A.W. Hamzah, R. Mamat, Int. Commun. Heat. Mass., 73: 75-83 (2016).

11. R.S. Luciu, T. Mateescu, V. Cotorobai, T. Mare, Bul. Inst. Polit. Iasi, 55: 71-80 (2009).

12. O.S. Prajapati, A. Rajvanshi, Int. J. Nanosci. Ser., 11 (2012).

13. N. Bozorgan, N. Bozorgan, Int. J. Adv. Des. Manuf. Tech., 5 (2012).

14. P.K. Namburu, D.K. Das, K.M. Tanguturi, R.S. Vajjha, Int. J. Therm. Sci., 48: 290-302 (2009).

15. M. Rostamani, S. Hosseinizadeh, M. Gorji, J. Khodadadi, Int. Commun. Heat. Mass., 37: 1426-1431 (2010).

16. J. Bayat, A.H. Nikseresht, Int. J. Therm. Sci., 60: 236-243 (2012).

17. W.H. Azmi, K. Sharma, P. Sarma, R. Mamat, S. Anuar, V.D. Rao, Exp. Therm. Fluid. Sci., 51: 103-111 (2013).

18. S. Lee, S.-S. Choi, S. Li, and, J. Eastman, J. Heat Transf., 121: 280-289 (1999).

19. Y. He, Y. Jin, H. Chen, Y. Ding, D. Cang, H. Lu, Int. J. Heat. Mass. Tran., 50: 22722281 (2007).

20. X. Wang, X. Xu, S.U. S. Choi, J. Thermophys. Heat. Tr., 13: 474-480 (1999).

21. Y. Ding, H. Alias, D. Wen, R.A. Williams, Int. J. Heat. Mass. Tran., 49: 240-250 (2006).

22. Y. He, Y. Jin, H. Chen, Y. Ding, D. Cang, H. Lu, Int. J. Heat. Mass. Tran., 50: 22722281 (2007).

23. V.S. Korada, Int. J. Auto. Mech. Eng. (IJAME), 3: 265-278 (2011).

24. G.R. Ahmadi, D. Toghraie, Renew. Sust. Energ. Rev., 56: 454-463 (2016).

25. L.S. Sundar, K. Sharma, Int. J. Heat. Mass. Tran., 53: 1409-1416 (2010).

26. W. Duangthongsuk, S. Wongwises, Int. J. Heat. Mass. Tran., 52: 2059-2067 (2009). 
27. K. Leong, R. Saidur, S. Kazi, A. Mamun, Appl. Therm. Eng., 30: 2685-2692 (2010).

28. A. Durmuş, A. Durmuş, M. Esen, Appl. Therm. Eng., 22: 321-332 (2002).

29. T.-H. Shih, W.W. Liou, A. Shabbir, Z. Yang, J. Zhu, Comput. Fluids, 24: 227-238 (1995).

30. A. FLUENT, ANSYS FLUENT Theory Guide, (ANSYS Inc., USA, 2011).

31. A. Bejan, Porous and complex flow structures in modern technologies, (Springer, 2004).

32. W.H. Azmi, K.V. Sharma, R. Mamat, A.B.S. Alias, I. Izwan Misnon, IOP Conf. Series: Mat. Sci. Eng., 36: 1 - 6 (2012).

33. S.E.B. Maïga, C.T. Nguyen, N. Galanis, G. Roy, Superlattice. Microst., 35: 543-557 (2004).

34. M. Rostamani, S.F. Hosseinizadeh, M. Gorji, J.M. Khodadadi, Int. Commun. Heat. Mass., 37: 1426-1431 (2010).

35. P.K. Sarma, T. Subramanyam, P.S. Kishore, V.D. Rao, S. Kakac, Int. J. Therm. Sci., 41: 955-960 (2002).

36. W.H. Azmi, K.V. Sharma, P.K. Sarma, R. Mamat, S. Anuar, L. Syam Sundar, Appl. Therm. Eng., 73: 294-304 (2014). 